\title{
Numerical Investigation of Wave-Induced Flow in Mound-Channel Wetland Systems
}

\author{
Yongqian Yanga,*, Jennifer L. Irish ${ }^{\mathrm{a}}$, Scott A. Socolofsky ${ }^{\mathrm{b}}$ \\ ${ }^{a}$ Department of Civil and Environmental Engineering, Virginia Tech, Blacksburg, VA, USA. \\ ${ }^{b}$ Department of Civil Engineering, Coastal and Ocean Engineering Division, Texas A\&M University, \\ College Station, TX, USA.
}

\begin{abstract}
Coastal wetlands are an important ecosystem in nearshore regions, but they are also significant in affecting the flow patterns within these areas. Wave-induced flow in wetlands has complex circulation characteristics because of the interaction between waves and plants, especially in discontinuous vegetation. Here, a numerical investigation is performed to analyze the wave-averaged flow in vegetated mound-channel systems. Different water levels, vegetated conditions, and mound configurations are studied with the COULWAVE (Cornell University Long and Intermediate Wave) Boussinesq model.

Model simulations show rip currents in the mound-channel systems, whose strength varies with different mound separation distances. The relative influence of vegetation depends on both mound configuration and water level. Approximately a 15\% change in significant wave height results as waves propagate over the vegetated mounds, while up to a $75 \%$ decrease in the mean shoreward flow speed through vegetation is observed. In addition, vegetation influences the spatial distribution of mean water level within the wetlands. Dimensional analysis shows that rip current strength and primary circulation size depend on mound spacing, water depth, wave height, and vegetation cover.

Keywords: Wetlands, Vegetated wave dissipation, Circulation, COULWAVE, Boussinesq model
\end{abstract}

\footnotetext{
*8 Patton Hall, 750 Drillfield Drive, Department of Civil and Environmental Engineering, Virginia Tech, Blacksburg, VA, USA.

Email address: yongqian@vt.edu (Yongqian Yang)

Preprint submitted to Coastal Engineering

April 30, 2015
} 


\section{Introduction}

As a transition region between ocean and land, wetlands are significant ecosystems that maintain water quality, provide natural habitat for a variety of species, and slow down erosion (Gaciaa and Duarteb, 2001; Shutes, 2001; Thullen et al., 2002). Besides its ecological function in coastal regions, wetland vegetation also influences wave dynamics. During the past two decades, studies have elucidated the potential of coastal wetlands to mitigate flow impact in extreme events and protect onshore infrastructure (e.g., Kobayashi et al., 1993; Loder et al., 2009; Shafer et al., 2003; Wamsley et al., 2010). With the projected increase in extreme weather events from global climate change and the rising population at the coast, using vegetation as a natural coastal buffer from wave impact remains an attractive research topic, especially in developing countries with wide coastlines.

In previous research, two common methods for studying waves in wetlands are scaled laboratory experiments with artificial or live vegetation (e.g., Anderson and Smith, 2014; Augustin et al., 2009; Bouma et al., 2005, 2010; Vandenbruwaene et al., 2011) and numerical simulations (e.g., Huang et al., 2011; Suzuki et al., 2012). Though these studies are efficient in learning the wave height transformation through vegetation coverage and calibrating the drag effect by vegetation, their bathymetric layouts have been relatively simple. Bathymetry in these studies is either constant depth or a plane slope, while in reality wetlands typically consist of vegetated mounds separated by channels.

In addition, no studies have focused on the quantification of vegetation's effect on the wave-induced flow circulation within wetlands. Rip currents are seaward jet flows from the surf zone with relatively higher velocity. They are commonly observed in nearshore regions with varying bathymetry, especially bar-channel systems. The variability in bathymetry induces alongshore variation of wave breaking around the bar-channel system, causing relatively more intense breaking across the bars. The process of wave pump model for rip current (e.g., Nielsen et al., 2001, 2008) by wave breaking raises water to higher level above the bars, compared with water level in the channels. This mechanism results in variations in significant wave height and mean water level distributions, which provides the primary 
driving force for alongshore flows feeding rip channels (Dalrymple et al., 2011; MacMahan et al., 2006). Rip currents are important processes to transport coastal pollutants, nutrients and sediments seawards, which may also cause erosion to shorelines. Since both natural and constructed wetlands typically consist of mound-channel systems, it is necessary to study the characteristics of rip current potential within these areas. Though similar to typical rip current phenomenon in bar-channel bathymetry, the circulation characteristics within discontinuous wetlands tend to be more complex.

Because of the transient nature of rip currents, field studies with stationary instrument deployments suffer from the difficulty in measuring changing bathymetry and flow patterns simultaneously (e.g., Haller et al., 1997; MacMahan et al., 2006). Basin-scale laboratory experiments could provide controlled conditions with better repeatability, but the tradeoff between measurement resolution and instrument interaction may affect the accuracy of the results. In these aspects, numerical simulation has its edge over field and laboratory studies. Using a basin-scale laboratory experiment and the COULWAVE Boussinesq model with emergent and near-emergent vegetation setups, Augustin et al. (2009) observed that wave height through a continuous rectangular vegetation region decreased more significantly than in the adjacent non-vegetated area. The generated alongshore wave height gradient then attempted to reach equilibrium with energy focusing towards the low wave height area, resulting in locally higher wave height behind the vegetation patch. Bradley and Houser (2009) observed an increase in wave height through a distance of the submerged seagrass in their field experiment. A similar wave height increase could be predicted by the model of Méndez et al. (1999), which incorporated the effect of wave reflection. Bradley and Houser (2009) hypothesized that wave height increase was attributed to the seagrass blades' obstruction acting like a bathymetric step that decreased wavelength and increased wave height through shoaling. Overall, these various phenomena in previous research imply that wave height evolution within vegetation is case-dependent and difficult to predict. This complexity may be further amplified in complex vegetated mound-channel bathymetry. Moreover, the efficiency of vegetation in wave dissipation is dependent on various parameters, such as stem stiffness, density and incident flow conditions (e.g., Bouma et al., 2005; Ondiviela et al., 2014; Paul 
et al., 2011; Vandenbruwaene et al., 2015), and significant protection against flow impact is not always guaranteed. For instance, according to a literature review by Ondiviela et al. (2014), seagrass does not protect the shoreline in all cases, and the optimal setups are with shallow depth and low-energy wave conditions. Vandenbruwaene et al. (2011) also reports potential flow acceleration within discontinuous vegetation patches.

This paper focuses on a more complicated bathymetric layout with a mound-channel system, whose prototype is Dalehite Cove in Galveston Bay, Texas, US. First, we introduce the laboratory experimental design used for model validation and the numerical model background. Then, model calibration and validation are conducted with experimental data. Third, numerical results of significant wave height, rip current, water level distribution, and swirling strength of the mean flow are analyzed. Finally, two dimensionless relations for these flow phenomena are developed, followed by conclusions.

\section{Methodology}

\subsection{Wetland Layout}

Truong (2011) and Truong et al. (2014) conducted experiments in a $36.6 \times 22.9 \times 1.5$ m wave basin in the Haynes Coastal Engineering Laboratory at Texas A\&M University, US (Figure 1). Three concrete conical-frustum mounds with $5.38 \mathrm{~m}$ bottom diameter, $2.02 \mathrm{~m}$ top diameter and $0.08 \mathrm{~m}$ height were constructed in a row $20.55 \mathrm{~m}$ from the wavemaker, representing the mounds in Dalehite Cove. The scale factor between the physical model and the prototype was $1: 6.5$, using Froude scaling based on surveys by HDR Engineering, Inc in August 2009. The vegetation was represented by $0.016-\mathrm{m}$ diameter and $0.077-\mathrm{m}$ height rigid wooden dowels affixed to the tops of the mounds and two wave conditions. The total stem number was 154, resulting in a stem density with 48 stems $/ m^{2}$ (Figure 1 in Truong et al. (2014)). Three distances between mounds' centers $(S=5.48 \mathrm{~m}, 7.02 \mathrm{~m}$ and $8.66 \mathrm{~m})$, two water levels $(0.50 \mathrm{~m}$ and $0.36 \mathrm{~m}$ ), and two wave conditions (wave height $0.17 \mathrm{~m}$ and $0.06 \mathrm{~m}$ ) were tested in the experiments. An instrument array with 19 capacitance wave gauges and 5 Acoustic Doppler Velocimeters were mounted on a moving bridge to map water surface 
elevation and induced current along cross-shore regions. Both non-vegetated and vegetated mounds were tested for each setup to study the influence of vegetation. More details about the experimental design are described in Truong (2011) and Truong et al. (2014).

A reference wave gauge was fixed in the offshore region to estimate the repeatability of the incident wave condition. Most experimental trials had approximately $5 \%$ variability in the wave gauge measurements. The accuracy of the Nortek Vectrino ADVs used in the experiment was $0.5 \%$ of the measured value plus $1 \mathrm{~mm} / \mathrm{s}$ uncertainty. For the measured current range in the experiments, the total theoretical uncertainty of ADV measurement was within 1\%. More details about the experimental data analyses are described in Truong (2011) and Truong et al. (2014).

\subsection{Numerical Model Theory}

In research of wave propagation in shallow and intermediate depth conditions, the Boussinesq-type equations are widely applied in both one- and two-dimensional horizontal applications. In previous studies, Boussinesq modeling was also successfully applied in research of rip current in bar-channel system and jet-like current by bathymetry variability (e.g., Chen et al., 1999, 2000). The numerical model used here, COULWAVE, is originally based on the Boussinesq-type equations in Liu (1994), with several additional terms to consider the effect of bottom friction and wave breaking. This depth-integrated model is applicable to simulation of fully nonlinear and weakly dispersive waves over variable bathymetry (Lynett and Liu, 2002; Lynett et al., 2008). Defining the dimensionless variables as,

$$
\text { variables as, }
$$

$$
\begin{gathered}
(x, y)=\frac{\left(x^{\prime}, y^{\prime}\right)}{\lambda}, \quad z=\frac{z^{\prime}}{h_{o}}, \quad t=\frac{\sqrt{g h_{o}} t^{\prime}}{\lambda} \\
h=\frac{h^{\prime}}{h_{o}}, \quad \zeta=\frac{\zeta^{\prime}}{a_{o}}, \quad p=\frac{p^{\prime}}{\rho g a_{o}} \\
(u, v)=\frac{\left(u^{\prime}, v^{\prime}\right)}{\varepsilon \sqrt{g h_{o}}}, \quad w=\frac{w^{\prime}}{\varepsilon / \mu \sqrt{g h_{o}}}
\end{gathered}
$$

the dimensionless governing equations (continuity and momentum equations) are (Lynett and Liu, 2002): 


$$
\frac{1}{\varepsilon} \frac{\partial h}{\partial t}+\frac{\partial \zeta}{\partial t}+\nabla \cdot\left[(\varepsilon \zeta+h) \mathbf{u}_{\alpha}\right]+\text { H.O.T. }=O\left(\mu^{4}\right),
$$

$$
\frac{\partial \mathbf{u}_{\alpha}}{\partial t}+\varepsilon \mathbf{u}_{\alpha} \cdot \nabla \mathbf{u}_{\alpha}+\nabla \zeta+\text { H.O.T }+R_{f}-R_{b}=O\left(\mu^{4}\right),
$$

where $h$ is the local water depth, $\zeta$ is the free surface elevation, $\mathbf{u}_{\alpha}=\left(u_{\alpha}, v_{\alpha}\right)$ is the reference horizontal velocity vector at $z_{\alpha}$ from still water level (Liu, 1994; Nwogu, 1993), $R_{f}$ is the bottom friction effect, $R_{b}$ is the wave breaking effect, $\varepsilon$ is the ratio between wave amplitude and depth $\left(\frac{a_{o}}{h_{o}}\right)$ for nonlinearity, $\mu$ is the ratio between depth and wavelength $\left(\frac{h_{o}}{\lambda}\right)$ for frequency dispersion and H.O.T is the higher order nonlinear and dispersive terms in the order of $O\left(\mu^{2}\right)$ (e.g., Løvholt et al., 2013; Lynett and Liu, 2002; Lynett et al., 2008, 2002).

The influence of vegetation is accounted for within the bottom friction term, $R_{f}=f \frac{\mathbf{u}_{b}\left|\mathbf{u}_{b}\right|}{h+\zeta}$, where $f$ is the non-dimensional friction coefficient and $\mathbf{u}_{b}$ is the horizontal velocity vector at the bed. Such approximation for vegetation is reasonable for bulk roughness, given the difficulty and high computational cost in modeling individual plants in large domains. The higher quadratic bottom friction used to represent vegetation provides more resistance against incident flows, which could slow down wave celerity. In general, $f$ is in the range of $10^{-3}$ to $10^{-2}$ for a normal seabed (Lynett et al., 2008). Here, the background friction effect of the basin and the influence of vegetation on the mounds are calibrated using the experimental data (Section 3). There are three common choices of friction parameters for simulating the vegetation's effect, Manning coefficient (Loder et al., 2009), drag coefficient (Huang et al., 2011) and non-dimentional Darcy factor (Augustin et al., 2009). For this paper, the non-dimentional Darcy factor employed by Augustin et al. (2009) is used in the simulations.

Experimental setups of the three mound configurations, two water levels and two wave conditions are simulated with the model. In addition, to further study the influence of wetland mound-channel systems on flow characteristics, eight additional mound-channel configurations are simulated using the same water levels and wave conditions as the laboratory experiments (Section 4). 


\section{Model Calibration and Validation}

Since this study emphasizes the influence of vegetation on the flow circulation and wave dissipation within mound-channel wetland systems under different conditions, experimental data with two water levels $(0.50 \mathrm{~m}$ and $0.36 \mathrm{~m})$, three mound separation distances $(S=5.38$ $\mathrm{m}, 7.02 \mathrm{~m}$ and $8.66 \mathrm{~m})$ and two wave heights $(0.17 \mathrm{~m}$ and $0.06 \mathrm{~m})$ in both non-vegetated and vegetated setups are used for model calibration and validation. Regular waves with a 2-s period are used, which is scaled from the prevalent wind-wave range observed in natural coastal wetlands. The Courant number is set as 0.1 , and the grid size is chosen as $0.04 \mathrm{~m}$. In order to study the wave-averaged characteristics within these mound-channel systems, each simulation is run for 100 seconds to ensure a sufficient number of waves for time-averaging.

In the experiments, one offshore wave gauge was fixed seaward between the wavemaker and the edge of the 1:10 ramp in each experimental trial, providing reference records to verify the repeatability of the incident wave conditions from trial to trial. To ensure that the same incident wave condition is used in the numerical model, background friction coefficient is calibrated by best fit of numerical results to the experimental offshore wave gauge records. Figure 2 (a) and (b) show the comparison of free surface between the simulation and wave gauge measurement in the offshore region with $0.50-\mathrm{m}$ and $0.36-\mathrm{m}$ water levels. It is observed that, even with the same setup and incident wave condition, the experimental records between trials are slightly different in amplitude (circles and triangles in Figure 2 (a) and (b)), so the simulated incident wave conditions can be regards as identical to experiments. Figure 2 (c) and (d) show the comparison of free surface between the simulations and wave gauge measurements at $x>22 \mathrm{~m}$. Though the time series between the two are not perfectly matched in (c) and (d) due to the increased non-linearity effect observed both in the experiments and in the simulations, the corresponding significant wave heights are still in good agreement. Model validation is completed by comparing experimental significant wave heights $\left(H_{s}\right)$ with numerical results. Significant wave height is calculated as four times the standard deviation of free surface time series, which is equivalent to four times the square root of moment of the wave spectra. To ensure analysis only of the stationary 
condition, the first few seconds of the simulated record are omitted from this calculation. Measurement from positions with repeatable significant wave heights (approximately 5\% uncertainty) were used for in model validation.

Percent root mean square of error $(\% R M S E)$ of the $H_{s}$ difference between experimental and numerical data is used to assess model validation:

$$
\% R M S E=\frac{\sqrt{\frac{\sum\left(H_{s, \text { exp }}-H_{s, \text { num }}\right)^{2}}{N}}}{\frac{\sum H_{s, \text { exp }}}{N}} \times 100 \%,
$$

where $H_{s, \exp }$ and $H_{s, n u m}$ are the experimental and numerical significant wave heights, respectively. The vegetation friction coefficients are determined according to the wave height propagation through the vegetated mounds, calibrated as 0.10 for $0.50 \mathrm{~m}$ depth and 0.15 for $0.36 \mathrm{~m}$ depth. The higher vegetation friction in shallower depth is a result of stronger vegetation resistance through water column, and is consistent with the calibration results in Augustin et al. (2009). The \%RMSE values of all validated experimental scenarios are summarized in Table 1 . In most setups, the validation criteria $\% R M S E$ values are around $5 \%$, with RMSE between 0.004 and $0.013 \mathrm{~m}$. In addition, phase lags of free surface are calculatied from 21 spatial location pairs per mound spacing for both the experimental data and the simulation results. The differences in experimental and modeled phase lags, estimated using the root mean square erro, are about $0.6 \mathrm{rad}$ (or 10\%). Given the potential effect of the dynamic wave absorption at the wavemaker and the recirculation currents in the basin due to imperfect symmetry during the experiments, this phase lag difference between experiment and modeling is acceptable.

In addition, simulated mean currents through five cross-shore transects between the mounds are compared with ADV measurements. Since the ADVs were used to measure velocity at a single point, at 0.4 times the still-water depth above the bottom, it is not directly comparable with the modeled depth-integrated velocity. Due to the concentration of wave mass transport in the upper water column, especially near the mound tops, ADV measurements below the troughs poorly resolve the induced currents (e.g., Faria et al., 2000; Haller et al., 2002; Svendsen, 2006). Thus, we use correlation statistics to evaluate model perfor- 
mance with respect to the ADV measurements, which will estimate the cross-shore profiles of velocity of experiment and simulation. Among all the experimental setups with 2-s regular waves, $60 \%$ and $71 \%$ of the cross-shore transects yield p-values lower than 0.10 and 0.15 when the ADV measurements and model results are compared. In this study, p-value represents the probability of rejecting the null hypothesis of non-correlation when the hypothesis is true. With p-value smaller than significance level, the correlation between experiment and simulation is significant (e.g., Ott and Longnecker, 2008). So with the significance level $\alpha=0.10$ and $\alpha=0.15$ for null-correlation hypothesis test in statistics, $60-70 \%$ of the modeled cross-shore transects are correlated with the measurements, while the discrepancy in other locations could be attributed to the different data acquisition methods (i.e., point measurement at specific depth by ADV versus depth-integrated velocity by modeling).

Based on the validations with significant wave height and mean current, the comparison results demonstrate satisfactory model performance.

\section{Numerical Results}

\subsection{Wave Reflection Influence}

To determine if wave reflection is a significant phenomenon in the model setup, a three wave gauge array is used in the numerical model (Isaacson, 1991; Mansard and Funke, 1980). In every simulation, two three-gauge arrays are located in the offshore region aligned with the mound and the channel, respectively. The reflection coefficients in all simulations are less than $7.6 \%$ (Table 1). Since the reflection coefficient remains low in all setups (similar to Anderson and Smith (2014)), the effect of wave reflection is assumed to be negligible in the following analyses.

\subsection{Mean Flow Field Characteristics}

\subsubsection{Mound Spacing Influence on Current}

Variability in bathymetry has a significant influence on rip current scale and strength (e.g., Dalrymple et al., 2011; MacMahan et al., 2006). Here, we analyse the simulation results to determine the influence of the mound-channel configuration on rip currents in 
wetlands. Figure 3 shows the time-averaged velocity fields and the spatial contours of mean water level (MWL) for the three non-vegetated mound configurations with two water levels. Since the overall setups are all symmetric about the centerline of the domain at $y=11.45$ $\mathrm{m}$, only the subdomains around the centerline are shown. The wave pump process lifts water above the mounds, leading to MWL gradient towards the channels. Rip currents driven by the wave pumping effect are observed in all setups, with shore-directed currents flowing over the mounds and feeding into along-coast channels behind the mounds. For the cases using a 0.50-m water level, the MWL gradient between wave setdown at and seaward of the mounds $(x<22 \mathrm{~m})$ and wave setup shoreward of the mounds $(x>23 \mathrm{~m})$ becomes more gradual with increasing mound separation. The local mean water depressions in channels are greatest for the narrowest mound separation $(5.48 \mathrm{~m})$, which also drives greater rip current strength (discussed later). With increasing mound separation, the wave setup region behind the mounds (warm color in the top panes in Figure 3) is both retreating shoreward and becoming less concentrated in the alongshore direction, leaving wider space for current diffusion. Similarly, these phenomena are observed in the shallower simulations (right panes in Figure 3). For the shallower water level case $(0.36 \mathrm{~m})$, the overall offshore wave setdowns and onshore wave setups are $40 \%$ and $30 \%$ less than those for the $0.50-\mathrm{m}$ depth case, while the local water depressions in the rips are more obvious. These depressions in the shallower depth expand and shift shorewards with wider mound separation due to more channel space for wave energy diffusion.

The rip current systems are also dependent on bathymetry (e.g., Brander and Short, 2000; Brander, 1999). To study the relationship between rip current strength and mound separation, additional scenarios with eight new mound separation distances $(S=6.02 \mathrm{~m}$, $6.52 \mathrm{~m}, 7.52 \mathrm{~m}, 8.02 \mathrm{~m}, 9.02 \mathrm{~m}, 9.72 \mathrm{~m}, 10.52 \mathrm{~m}$ and $11.32 \mathrm{~m})$ are simulated.The mean cross-shore current $(U)$ presented in Figure 4 is averaged in 1-m alongshore bins over the mound ((b) and (e)) in the basin's centerline and through the channel center between the bottom edges of two adjacent mounds ((a) and (d)). These cross-shore profiles of mean $U$ are shown in Figure 4 for both $0.50-\mathrm{m}$ and $0.36-\mathrm{m}$ water levels with the bathymetry. In shallower depth, the overall rip current amplitudes are less than the deeper setup (Figure 
4 (a) and (d)). For both water depths, rip current amplitude decreases with increasing mound separation distance, which illustrates that with more space in the channel for rip current development, the current strength tends to diffuse and become less concentrated (Figure 4 (a) and (d)). The cross-shore locations of maximum rip current shift shoreward as the channel widens. In contrast, the shoreward current amplitude over the mound is less sensitive to mound separation (Figure 4 (b) and (e)). However, the current over the mound persists high further inland with wider mound separation. As the channel widens, it is likely that the weaker rip current steepens the incident waves to a lesser extent. As a result, incident waves may propagate farther inshore before breaking in the wider channels. Others have shown that farther shoreward wave penetration through the rip channel could generate a longshore radiation stress gradient that opposes the longshore pressure gradient (e.g., Haller et al., 2002; MacMahan et al., 2006). According to numerical results in this study, similar opposing alongshore gradients of radiation stress and mean water level for wider mound separations are observed. This phenomenon may reduce the feeder flow into the rip channels shoreward of the mounds as mound separation widens. In turn, the previous feeder flow into the channel, which is redirected by the opposing radiation stress from the wider channel, may stay aligned behind the mound, resulting in higher current speed shoreward of the mound.

\subsubsection{Vegetation Effect on Significant Wave Height and Mean Current}

Figure 5 (a), (b), (f) and (g) show the cross-shore distribution of mean $U$ and $H_{s}$ over the mound and through the channel for the $0.50 \mathrm{~m}$ water level setups, with and without vegetation. Wave height is slightly dissipated on the vegetated mound (around $x=20-22$ $\mathrm{m})$, but shoreward of the mound, $H_{s}$ becomes higher than in the non-vegetated setups, regardless of the mound spacing (Figure $5(\mathrm{~b})$ ). The current strength over the mound is more sensitive to the roughness on the mound than to the mound separation distance. Unlike $H_{s}$, mean $U$ is consistently dampened over the vegetated mound, when compared with the non-vegetated setups (Figure $5(\mathrm{a})$ ). Through the channel, while the location of rip current maxima tends to move shoreward with increasing mound separation (see Section 4.2.1), 
vegetation tends to shift the maximum current's location seaward. With the closest mound separation $(5.48 \mathrm{~m})$, since the channel is as narrow as $0.10 \mathrm{~m}$ between the adjacent edges of two mounds' bottoms, the direct damping effect from the vegetated mound extends into the rip, significantly reducing the wave height in the channel. When mounds are separated farther, the extension of direct damping effect from mound vegetation becomes weaker into the channels. At the same time, the weakened current in the wider channels of vegetated setups (Figure 5 (f)) allows waves to break farther inshore, so the corresponding wave heights in the rips are slightly higher (less than 10\%) than in the non-vegetated setups (Figure 5 $(\mathrm{g}))$.

Similarly, Figure 5 (c), (d), (h) and (i) show profiles of mean $U$ and $H_{s}$ for the 0.36m water level. Mean $U$ over the mound has similar trends as the deeper cases, but the differences in $H_{s}$ between the non-vegetated and vegetated cases are more significant. With the shallower water level, the higher equivalent roughness results in much greater flow speed dissipation (Figure $5(\mathrm{c})$ ). Such a sudden and sharp drop in current speed may significantly shorten wavelength within the vegetation on the mounds compared to the non-vegetated case. When the effect of velocity loss within the vegetation is sufficiently strong, the energy of the shortened waves would accumulate in vertical direction, which leads to increasing wave height over and behind the vegetated mounds (Figure $5(\mathrm{~d})$ ). Through the channel, the current does not decrease consistently in the cross-shore direction, as in the deeper cases. Rather, the seaward shifting of maximum current location by vegetation causes $23 \%-38 \%$ higher velocities for about a 2-m distance in the rip for all mound separations (Figure 5 (h)), compared with non-vegetated case. In wider channels, the amplitude of rip currents in vegetated cases becomes even higher than the non-vegetated cases. It is likely that the higher resistance of emergent vegetation forces more flow into the channels, especially with wider mound separation that provides more space for channelization. Increasing wave height is observed in all shallower channels in vegetated setups. However, it should be noted that such wave height increase is not caused by the occurrence of farther inshore wave breaking, which is the mechanism in the deeper water level setups. Due to the stronger rip current in the shallow-depth vegetated setups, which is $23 \%-38 \%$ higher than the non-vegetated 
case for a 2-m distance in the rip, incident waves in the channel are significantly steepened (30\% - 51\% increase in significant wave height in Figure 5 (i)); this is similar to the finding of Haller et al. (2002) for bar-rip systems. As a result, wave heights in the vegetated cases in Figure 5 (i) increase over and inshore of the mounds, then decrease immediately due to wave breaking.

Figure 6 shows the percent change of maximum current amplitude, $\triangle U=\frac{U_{c, \text { vegetated }}-U_{c, n o n}}{U_{c, \text { non }}} \times$ $100 \%$, caused by vegetation for mound spacings, where $U_{c}$ is the cross-shore maximum current amplitude. Over mounds, the current amplitude is consistently reduced by vegetation in all configurations. The trends describing current amplitude reductions are not sensitive to the mound separation distance for either of the two water levels. The extent of currentamplitude damping in the $0.36-\mathrm{m}$ depth case $(75 \%)$ is greater than that for the deeper case (40\%), which shows that vegetation resistance in shallower water plays a more significant role in dissipating current over the mounds. In contrast, the percent current-amplitude change through the channels varies with mound separation. In the channels, the percent current-amplitude change trends of the two water depth setups are similar, but the shallower depth case becomes positive in seven of the mound configurations, while the deeper case always remains negative. Thus, with higher roughness on the mound and sufficient channel width, the rip current may be amplified by vegetation. When considering sediment transport, such amplification might result in shoreline erosion or widening of channels.

\subsection{Spatial Circulation Characteristics}

To study the time-averaged, spatial circulation characteristics, the simulated mean velocity field, rather than the instantaneous one, is used for analysis. Vorticity is the classic parameter used to study circulation structure. However, besides the vortical core, the vorticity also catches shearing motions near boundaries. As a result, the primary rotation vortices are contaminated by this unwanted interference (e.g., Adrian et al., 2000; Nicolau del Roure et al., 2009). Since the large-scale vortices are of interest here, it is preferable to minimize the effect of the boundary shear on the analysis.

Swirling strength is another method for identifying vortical structure from velocity fields 
(e.g., Adrian et al., 2000; Zhou et al., 1999). Swirling strength is computed from the local velocity gradient tensor,

$$
D_{v}=\left[\begin{array}{ll}
\frac{\partial u}{\partial x} & \frac{\partial u}{\partial y} \\
\frac{\partial v}{\partial x} & \frac{\partial v}{\partial y}
\end{array}\right]
$$

$D_{v}$ has a pair of complex conjugate eigenvalues, whose positive imaginary part is the local swirling strength. The reciprocal of swirling strength is the period of a particle trajectory around the axis of the real part. Since pure shear flow has infinite elliptical trajectory, which corresponds to infinite orbit period and zero swirling strength, the non-zero vorticity values in shear layers without local swirling motion are eliminated in the swirling strength field (Adrian et al., 2000).

Figure 7 (a) - (f) show the swirling strength of time-averaged flow for the $S=5.48$ $\mathrm{m}, 7.02 \mathrm{~m}$ and $8.66 \mathrm{~m}$ mound separations with the $0.50-\mathrm{m}$ water level. In the following discussion, the size of the primary swirling cores is quantified using a swirling strength threshold of $0.01 \mathrm{~s}^{-1}$. The primary vortices marked by the red boxes in Figure 7 have a clockwise rotation. Both non-vegetated and vegetated setups are analyzed to study the influence of vegetation on the large-scale circulation. Sizes of both the primary swirling cores and the secondary circulations downstream (after $x=25 \mathrm{~m}$ ) increase with mound separation distance. This increase can be attributed to the larger space for vortex development in the wider channels. In the presence of vegetated mounds, the size of the primary swirling cores decreases, whereas the secondary cores downstream expand. As observed in Figure 5 (a) and (f), cross-shore current amplitudes are reduced by vegetation both over the mounds and in the channels between $x=20-23 \mathrm{~m}$. Such velocity dissipation is in the same position as the primary vortex, which accounts for the vortex size reduction. In contrast, the secondary circulations increase in size under the influence of vegetation. This results from the increased reversed shoreward rip current (positive $U$ after $x>24 \mathrm{~m}$ in Figure 5 (f)). Since the positive, shoreward current behind the channel is an indication of secondary circulation (Haller et al., 2002), its increase could lead to stronger secondary vortices in vegetated setups. Moreover, the secondary circulations are modified into more circular 
shapes in the presence of vegetation.

Swirling strength of the same mound separations with $0.36-\mathrm{m}$ water level are shown in Figure $7(\mathrm{~g})$ - (l). Similar increase of the primary vortex size with the same mound separation as the $0.50-\mathrm{m}$ water level is found, but these primary circulations decrease in size more significantly in the presence of vegetation. In Figure $7(\mathrm{~g}),(\mathrm{h})$ and (i), the clockwiserotating primary swirling cores shown in the red boxes include both the red contoured area as well as the light blue contoured area. In contrast, the light blue contoured areas downstream of the marked cores in Figure $7(\mathrm{j}),(\mathrm{k})$ and (l) are secondary circulations rotating counter-clockwise. Besides the dissipation of the primary vortex, vegetation also forces the expanded secondary circulation seaward. Figure $5(\mathrm{~h})$ shows that the locations of cross-shore current flow reversal are shifted seaward to $x=22-24 \mathrm{~m}$ by vegetation, which moves the secondary circulations closer to the mounds. In addition, compared with the $0.50-\mathrm{m}$ water level case, the secondary circulations are more irregular in shape, for both non-vegetated and vegetated setups, which implies that the overall circulation field is more complicated in shallower depths.

\section{Discussion}

While the simulations here are completed only for a few mound-channel configurations, water levels and wave conditions, a dimensional analysis is performed to predict the rip current and mean circulation in other similar mound-channel systems for general applicability.

To predict rip current amplitude in different mound-channel systems, the parameters are analyzed in dimensionless form:

$$
\frac{U_{c}}{c_{o}}=f_{1}\left(\frac{S^{2}}{h_{c} \sqrt{H_{o} h_{c}}}\right),
$$

where $S$ is the mound separation distance, $c_{o}$ is the deep-water wave celerity by linear wave theory $\left(c_{o}=\sqrt{\frac{g}{k}}\right), H_{o}$ is the deep-water equivalent wave height by linear transformation, $h_{c}$ is the depth in the wetland channel and $U_{c}$ is the rip current amplitude. Figure 8 shows Equation 5 with numerical results from all mound configurations. With increasing 
mound separation distance, the overall trend of the dimensionless rip current amplitude is decreasing, until $\frac{S^{2}}{h_{c} \sqrt{H_{o} h_{c}}}>4200$. For $\frac{S^{2}}{h_{c} \sqrt{H_{o} h_{c}}}<4200$, the data approximately follow a logarithmic trend. When $\frac{S^{2}}{h_{c} \sqrt{H_{o} h_{c}}}>4200$, the dimensionless rip current amplitude is more complex, first increasing then decreasing with dimensionless spacing. It can be hypothesized that with sufficiently wide mound separation, rip currents tend to vanish, as shown by the trend of $\frac{U_{c}}{c_{o}}$ approaching zero with the increasing dimensionless mound spacing, $\frac{S^{2}}{h_{c} \sqrt{H_{o} h_{c}}}$. Using eight mound-channel configurations, $S=6.02 \mathrm{~m}, 6.52 \mathrm{~m}, 7.52 \mathrm{~m}, 8.02 \mathrm{~m}, 9.02 \mathrm{~m}$, $9.72 \mathrm{~m}, 10.52 \mathrm{~m}$ and $11.32 \mathrm{~m}$, the regression equation shown in Figure 8 is:

$$
\frac{U_{c}}{c_{o}}=0.029 \log \left(\frac{S^{2}}{h_{c} \sqrt{H_{o} h_{c}}}\right)-0.272 \text { when } \frac{S^{2}}{h_{c} \sqrt{H_{o} h_{c}}}<4200 .
$$

This formula can be used as a first estimate of the rip current amplitude in wetland moundchannel systems, when $\frac{S^{2}}{h_{c} \sqrt{H_{o} h_{c}}}<4200$. The $R^{2}$ of the regression equation is 0.931 (for $\frac{S^{2}}{h_{c} \sqrt{H_{o} h_{c}}}<4200$ ), and $100 \%$ of these rip current amplitudes are within $20 \%$ of the values predicted by this equation. Simulation with the experimental $S=5.48 \mathrm{~m}, 7.02 \mathrm{~m}$ and $8.66 \mathrm{~m}$ are used to validate this regression equation (star symbols in Figure 8), with all simulations of $\frac{S^{2}}{h_{c} \sqrt{H_{o} h_{c}}}<4200$ falling in reasonable range of the prediction.

In the previous sections, the friction coefficients for vegetation in the simulations are chosen based on the validation with vegetated experimental data. To study the effect of different vegetated conditions (e.g., how frictional resistance is modified by density, species, flexibility) on the primary circulation, additional simulations with differing friction coefficients are performed using $S=5.48 \mathrm{~m}, 7.02 \mathrm{~m}$ and $8.66 \mathrm{~m}$ mound separations. Similarly, a dimensional analysis is conducted as:

$$
\frac{C^{0.5}}{h_{c}}=f_{2}\left(\frac{f_{v e g}}{f_{c}} \frac{H_{o}}{S}\right),
$$

where $f_{\text {veg }}$ is the vegetation's friction coefficient, $f_{c}$ is the non-vegetated friction in the wetland channels, and $C$ is the area of the marked swirling cores in Figure 7 (swirling strength $\left.>0.01 \mathrm{~s}^{-1}\right)$. The relation of Equation 7 is shown in Figure 9, and the data follow a power distribution. Using the simulated data shown as hollow circles and triangles in Figure 
7 , the regression equation is:

$$
\frac{C^{0.5}}{h_{c}}=10.350\left(\frac{f_{v e g}}{f_{c}} \frac{H_{o}}{S}\right)^{-0.091} .
$$

The $R^{2}$ for this regression equation is 0.523 . Equation 8 , which estimates simulated primary circulation size to within $20 \%$, catches the main size trend. $86 \%$ of simulations are within the $20 \%$ predictive range. To validate the regression equation shown in Figure 9, additional vegetated simulations are completed with several of the eight additional mound separations discussed in previous sections (stars in Figure 9). The results with $f_{v e g}=0.10$ for $0.50-\mathrm{m}$ depth and $f_{\text {veg }}=0.15$ for $0.36-\mathrm{m}$ depth are reasonably represented by Equation 8 . As a result, Equation 8 can be used to preliminarily estimate the extent of significant circulation as a function of mound-channel configuration. Future studies on the influence of other parameters, such as mound characteristics, might improve the regression.

Table 2 applies the empirical equations, Equation 6 and Equation 8, to field scale at Dalehite Cove in Galveston Bay, TX, for both normal daily and storm conditions. The predicted rip current amplitudes are within the typical range of rip currents in nature (i.e., generally $0.3-0.6 \mathrm{~m} / \mathrm{s}$, and up to $2.4 \mathrm{~m} / \mathrm{s}$ in extreme case), demonstrating the equation yields reasonable estimates for rip current strength in mound-channel wetland systems. Field studies to measure rip current strength and primary circulation over a range of conditions are needed to assess the equations' performance.

\section{Summary \& Conclusions}

A numerical model investigation with COULWAVE is carried out to study the waveinduced flow in wetland mound-channel systems. The layouts with relatively complicated bathymetry provide a more realistic model of natural coastal wetlands. Numerical results show good agreement with experimental data for twelve different conditions (i.e. water level, vegetated condition and mound separation), and the parameter set for study is extended to include additional mound-channel setups.

Rip currents and feeder flows are observed within the wetland mound-channel systems. 
Mound separation influences both the rip current strength and the location of its maxima. A logarithmic relation is obtained between normalized rip current strength and normalized mound separation distance for the range of $\frac{S^{2}}{h_{c} \sqrt{H_{o} h_{c}}}<4200$. Though the rip current strength is less predictable when $\frac{S^{2}}{h_{c} \sqrt{H_{o} h_{c}}}>4200$, the rip current tends to vanish when the mound separation is sufficiently wide.

Vegetation effects on mean currents and on wave heights interact with each other. Changes in rip currents influence how far wave breaking extends into the channel, which in turn affects the mean water level distribution and current pattern in the mound-channel system. Mean cross-shore velocities are always dissipated by vegetation over mounds, but velocities are increased or reduced through the channel as a consequence of the mound vegetation, depending on mound separation and water level. Vegetation reduces wave heights over the mound and in the narrower channel setups for the 0.50-m depth case, while it increases wave height both over the mound and through the channel in the 0.36-m depth case. Because of these complex interactions, in general, small mound separation generates higher rip currents, while the damping effect of vegetation in channels decreases with much larger mound separation. Optimal mound configuration should be chosen, accounting for the compromise between vegetation concentration and flow impact attenuation.

Swirling strength indicates that vegetation tends to decrease the primary vortex size in the vicinity of the mounds and expand the secondary circulation inshore, which could be attributed to the variation in mean velocity distribution caused by vegetation.

In closing, wetlands are an important ecosystem and coastal buffer zone from extreme events. The results in this paper provide further understanding about how vegetation reduces or amplifies flow impacts within mound-channel wetlands. Since circulation patterns are a significant factor for the long-term stability of these mound-channel systems, the logarithmic and power-form relations for normalized rip current strength and normalized primary vortex size are important for flow estimates to ensure the feasibility of wetland restoration or protection initiatives. These two relationships can be used as first estimate in practical application for current and circulation conditions within discontinuous wetlands, for example constructed mound-channel systems with salt marsh vegetation (e.g., Spartina alterniflora). 
Further research is needed to understand the influence of other characteristics, such as mound height and shape.

\section{Nomenclature}

$a$ wave amplitude

$c_{o} \quad$ wave celerity in deep water

$f \quad$ friction coefficient

$h$ local water depth

$h_{c} \quad$ water depth in channel within wetlands

$k \quad$ wave number

$\mathbf{u}_{\alpha} \quad$ reference horizontal velocity $\left(u_{\alpha}, v_{\alpha}\right)$ at $z_{\alpha}$ from still water

$\varepsilon \quad$ measure of nonlinearity, $\frac{a}{h}$

$\zeta$ free surface

$\mu \quad$ measure of frequency dispersion, $k h$

$C \quad$ area of primary swirling strength

$D_{v} \quad$ local velocity gradient tensor

$H$ incident wave height

$H_{o} \quad$ offshore wave height in deep water

$H_{s} \quad$ significant wave height

$R_{b} \quad$ wave breaking effect

$R_{f} \quad$ bottom friction effect

\%RMSE percentile root mean square of difference between numerical and experimental data

$S$ distance between the centers of adjacent mounds

$U_{c} \quad$ rip current amplitude

$\lambda \quad$ wavelength 


\section{Acknowledgements}

This material is base on work supported by the National Sea Grant College Program of the U.S. Department of Commerce's National Oceanic and Atmospheric Administration (Grant No. NA14OAR4170102) and the National Science Foundation (Grant No. CMMI1206271). This work used resources of Advanced Research Computing at Virginia Tech. Y. Yang would like to express his special thank to Dr. Lynett in University of South California for providing the source code of COULWAVE. Help from staff and students who conducted the experiments in the Haynes Coastal Engineering Laboratory at Texas A\&M University is acknowledged. Model data in this study will be provided by the corresponding auther (Yongqian Yang, email: yongqian@vt.edu) upon request.

\section{References}

Adrian, R., Christensen, K., Liu, Z.C., 2000. Analysis and interpretation of instantaneous turbulent velocity fields. Experiments in fluids 29, 275-290.

Anderson, M.E., Smith, J., 2014. Wave attenuation by flexible, idealized salt marsh vegetation. Coastal Engineering 83, 82-92.

Augustin, L.N., Irish, J.L., Lynett, P., 2009. Laboratory and numerical studies of wave damping by emergent and near-emergent wetland vegetation. Coastal Engineering 56, 332-340.

Bouma, T., De Vries, M., Low, E., Peralta, G., Tanczos, I., van de Koppel, J., Herman, P.M.J., 2005. Trade-offs related to ecosystem engineering: a case study on stiffness of emerging macrophytes. Ecology $86,2187-2199$

Bouma, T., Vries, M.D., Herman, P., 2010. Comparing ecosystem engineering efficiency of two plant species with contrasting growth strategies. Ecology 91, 2696-2704.

Bradley, K., Houser, C., 2009. Relative velocity of seagrass blades: Implications for wave attenuation in low-energy environments. Journal of Geophysical Research: Earth Surface (2003-2012) 114.

Brander, R., Short, A., 2000. Morphodynamics of a large-scale rip current system at muriwai beach, new zealand. Marine Geology 165, 27-39.

Brander, R.W., 1999. Field observations on the morphodynamic evolution of a low-energy rip current system. Marine Geology 157, 199-217.

Chen, Q., Dalrymple, R.A., Kirby, J.T., Kennedy, A.B., Haller, M.C., 1999. Boussinesq modeling of a rip current system. Journal of Geophysical Research: Oceans (1978-2012) 104, 20617-20637. 
Chen, Q., Kirby, J.T., Dalrymple, R.A., Kennedy, A.B., Chawla, A., 2000. Boussinesq modeling of wave transformation, breaking, and runup. ii: 2d. Journal of Waterway, Port, Coastal, and Ocean Engineering $126,48-56$.

Dalrymple, R.A., MacMahan, J.H., Reniers, A.J., Nelko, V., 2011. Rip currents. Annual Review of Fluid Mechanics 43, 551-581.

Faria, A., Thornton, E., Lippmann, T., Stanton, T., 2000. Undertow over a barred beach. Journal of Geophysical Research: Oceans (1978-2012) 105, 16999-17010.

Gaciaa, E., Duarteb, C., 2001. Sediment retention by a mediterranean posidonia oceanica meadow: The balance between deposition and resuspension. Estuarine, Coastal and Shelf Science 52, 505-514.

Haller, M.C., Dalrymple, R., Svendsen, I., 1997. Experimental modeling of a rip current system, in: Proceedings of the 3rd International Symposium on Ocean Wave Measurement and Analysis, pp. 750-764.

Haller, M.C., Dalrymple, R.A., Svendsen, I.A., 2002. Experimental study of nearshore dynamics on a barred beach with rip channels. Journal of Geophysical Research: Oceans (1978-2012) 107, 14-1.

Huang, Z., Yao, Y., Sim, S.Y., Yao, Y., 2011. Interaction of solitary waves with emergent, rigid vegetation. Ocean Engineering 38, 1080-1088.

Isaacson, M., 1991. Measurement of regular wave reflection. Journal of Waterway, Port, Coastal, and Ocean Engineering 117, 553-569.

Kobayashi, N., Raichle, A.W., Asano, T., 1993. Wave attenuation by vegetation. Journal of waterway, port, coastal, and ocean engineering 119, 30-48.

Liu, P.L., 1994. Model equations for wave propagations from deep to shallow water. Advances in coastal and ocean engineering 1, 125-158.

Loder, N., Irish, J.L., Cialone, M., Wamsley, T., 2009. Sensitivity of hurricane surge to morphological parameters of coastal wetlands. Estuarine, Coastal and Shelf Science 84, 625-636.

Løvholt, F., Lynett, P., Pedersen, G., 2013. Simulating run-up on steep slopes with operational boussinesq models; capabilities, spurious effects and instabilities. Nonlinear Processes in Geophysics 20, 379-395.

Lynett, P., Liu, P.L.F., 2002. A numerical study of submarine-landslide-generated waves and run-up. Proceedings of the Royal Society of London. Series A: Mathematical, Physical and Engineering Sciences 458, $2885-2910$.

Lynett, P.J., Liu, P.L., Sitanggang, K.I., Kim, D.H., 2008. Modeling wave generation, evolution, and interaction with depth-integrated, dispersive wave equations coulwave code manual cornell university long and intermediate wave modeling package v. 2.0. Cornell University Long and Intermediate Wave Modeling Package .

Lynett, P.J., Wu, T.R., Liu, P.L.F., 2002. Modeling wave runup with depth-integrated equations. Coastal Engineering 46, 89-107. 
MacMahan, J.H., Thornton, E.B., Reniers, A.J., 2006. Rip current review. Coastal Engineering 53, 191-208.

Mansard, E.P., Funke, E., 1980. The measurement of incident and reflected spectra using a least squares method. Coastal Engineering Proceedings 1.

Méndez, F.J., Losada, I.J., Losada, M.A., 1999. Hydrodynamics induced by wind waves in a vegetation field. Journal of Geophysical Research: Oceans (1978-2012) 104, 18383-18396.

Nielsen, P., Brander, R.W., Hughes, M.G., 2001. Rip currents: observations of hydraulic gradients, friction factors and wave pump efficiency, in: Proc. Coastal Dynamics, p. 489.

Nielsen, P., Guard, P.A., Callaghan, D.P., Baldock, T.E., 2008. Observations of wave pump efficiency. Coastal engineering 55, 69-72.

Nwogu, O., 1993. Alternative form of boussinesq equations for nearshore wave propagation. Journal of waterway, port, coastal, and ocean engineering 119, 618-638.

Ondiviela, B., Losada, I.J., Lara, J.L., Maza, M., Galván, C., Bouma, T.J., van Belzen, J., 2014. The role of seagrasses in coastal protection in a changing climate. Coastal Engineering 87, 158-168.

Ott, R., Longnecker, M., 2008. An introduction to statistical methods and data analysis. Cengage Learning.

Paul, M., Bouma, T., Amos, C., 2011. Wave attenuation by submerged vegetation: combining the effect of organism traits and tidal current. Marine Ecology Progress Series 444, 31-41.

Nicolau del Roure, F., Socolofsky, S.A., Chang, K.A., 2009. Structure and evolution of tidal starting jet vortices at idealized barotropic inlets. Journal of Geophysical Research: Oceans (1978-2012) 114.

Shafer, D.J., Roland, R., Douglass, S.L., 2003. Preliminary evaluation of critical wave energy thresholds at natural and created coastal wetlands. Technical Report. DTIC Document.

Shutes, R.B.E., 2001. Artificial wetlands and water quality improvement. Environment international 26, $441-447$.

Suzuki, T., Zijlema, M., Burger, B., Meijer, M.C., Narayan, S., 2012. Wave dissipation by vegetation with layer schematization in swan. Coastal Engineering 59, 64-71.

Svendsen, I.A., 2006. Introduction to nearshore hydrodynamics. volume 24. World Scientific.

Thullen, J.S., Sartoris, J.J., Walton, W.E., 2002. Effects of vegetation management in constructed wetland treatment cells on water quality and mosquito production. Ecological Engineering 18, 441-457.

Truong, M.K., Whilden, K.A., Socolofsky, S.A., Irish, J.L., 2014. Experimental study of wave dynamics in coastal wetlands. Environmental Fluid Mechanics , 1-30.

Truong, M.K.P., 2011. Experimental study on wave transformation and nearshore circulation on a variable bathymetry in wetlands. Master's thesis, Texas A\&M University .

Vandenbruwaene, W., Schwarz, C., Bouma, T., Meire, P., Temmerman, S., 2015. Landscape-scale flow patterns over a vegetated tidal marsh and an unvegetated tidal flat: Implications for the landform properties of the intertidal floodplain. Geomorphology 231, 40-52. 
Vandenbruwaene, W., Temmerman, S., Bouma, T., Klaassen, P., De Vries, M., Callaghan, D., Van Steeg, P., Dekker, F., Van Duren, L., Martini, E., et al., 2011. Flow interaction with dynamic vegetation patches: Implications for biogeomorphic evolution of a tidal landscape. Journal of Geophysical Research: Earth Surface (2003-2012) 116.

Wamsley, T.V., Cialone, M.A., Smith, J.M., Atkinson, J.H., Rosati, J.D., 2010. The potential of wetlands in reducing storm surge. Ocean Engineering 37, 59-68.

Zhou, J., Adrian, R., Balachandar, S., Kendall, T., 1999. Mechanisms for generating coherent packets of hairpin vortices in channel flow. Journal of Fluid Mechanics 387, 353-396. 
Figure 1: (a) Side view of laboratory setup (in m) (modified from Truong (2011)); (b) measurement locations of wave gauge locations $(*)$ for $8.66 \mathrm{~m}$ mound separation, scaled from (a) to show the domain of interest.

Figure 2: Offshore free surface elevation (normalized by incident wave height) of two experimental trials (triangle and circle) and numerical data (solid line) with (a) 0.50-m water level and 0.17-m incident wave height; (b) 0.36-m water level and 0.06-m incident wave height. Free surface elevation (normalized by incident wave height) of two experimental trials (triangle and circle) and numerical data (solid line) at $x=22 \mathrm{~m}$ (behind the mounds) with (c) 0.50-m water level and 0.17-m incident wave height; (d) 0.36-m water level and 0.06-m incident wave height.

Figure 3: Time-averaged velocity fields and mean water levels (in m) of $0.50 \mathrm{~m} \mathrm{(a} \mathrm{-} \mathrm{c)} \mathrm{and} 0.36 \mathrm{~m}(\mathrm{~d}-\mathrm{f})$ water levels in non-vegetated setups (incident waves travel from left to right). Symmetry about the centerline of the domain is obtained in each simulation, so only subdomains around the centerline are shown.

Figure 4: Cross-shore profile of mean current profiles through the channel (a and d) and over the mound (b and e) with $0.50-\mathrm{m}$ ( $\mathrm{a}$ and $\mathrm{b}$ ) and $0.36-\mathrm{m}$ (c and d) water levels. The legend denotes the mound separation distances. Panes (c) and (f) show the side view of basin bed elevation through the mound centerline. Vertical dotted lines correspond to the edges of the mound, while horizontal dashed lines show $U=0$.

Figure 5: Cross-shore profiles of mean current and significant wave height over the mound $(\mathrm{a}-\mathrm{d})$ and channel (f - i). Panes (a), (b), (f) and (g) are for 0.50-m water level and 0.17-m incident wave height, while (c), (d), (h) and (i) are in 0.36-m water level and 0.06-m incident wave height. The legend denotes the mound separation distances and vegetated versus non-vegetated conditions. Panes (e) and (j) show the side view of basin bed elevation through the mound centerline. Vertical dotted lines correspond to the edges of and mound, while horizontal dashed lines show $U=0$.

Figure 6: Percent difference in mean current between non-vegetated and vegetated setups for different mound separations and water levels.

Figure 7: Swirling strength (in $\left.s^{-1}\right)$ for 0.50-m depth (a - f) and 0.36-m depth (g - l) cases. Panes (a) - (c) and (g) - (i) are non-vegetated setups with different mound separations, while (d) - (f) and (j) - (l) are the corresponding vegetated setups. The red rectangles mark the primary circulations on the middle mounds using a swirling strength threshold of $0.01 s^{-1}$. Incident waves travel from left to right.

Figure 8: Dimensionless relationship between mound separation distance and rip current amplitude. Stars denote simulations for validation. 
Figure 9: Dimensionless size of swirling strength versus friction coefficient on the top of mound. Stars denote simulations for validation.

Table 1: Model validation of significant wave height

\begin{tabular}{|c|c|c|c|c|c|c|c|}
\hline \multirow[t]{2}{*}{$S(\mathbf{m})$} & \multirow[t]{2}{*}{ Vegetated } & \multirow[t]{2}{*}{$\mathbf{h}(\mathbf{m})$} & \multirow[t]{2}{*}{$H(\mathrm{~m})$} & \multirow[t]{2}{*}{$f_{v e g}$} & \multirow[t]{2}{*}{ \%RMSE [RMS (m)] } & \multicolumn{2}{|c|}{ Reflection } \\
\hline & & & & & & channel & mound \\
\hline 5.48 & No & 0.50 & 0.17 & 0.001 & $2.67 \%[0.005]$ & $5.21 \%$ & $4.93 \%$ \\
\hline 5.48 & Yes & 0.50 & 0.17 & 0.100 & $4.22 \%[0.008]$ & $5.28 \%$ & $5.47 \%$ \\
\hline 7.02 & No & 0.50 & 0.17 & 0.001 & $6.39 \%[0.013]$ & $5.10 \%$ & $5.54 \%$ \\
\hline 7.02 & Yes & 0.50 & 0.17 & 0.100 & $5.40 \%[0.010]$ & $5.29 \%$ & $4.86 \%$ \\
\hline 8.66 & No & 0.50 & 0.17 & 0.001 & $4.79 \%[0.010]$ & $3.78 \%$ & $5.29 \%$ \\
\hline 8.66 & Yes & 0.50 & 0.17 & 0.100 & $4.65 \%[0.008]$ & $4.58 \%$ & $5.60 \%$ \\
\hline 5.48 & No & 0.36 & 0.06 & 0.001 & $2.71 \%[0.004]$ & $5.16 \%$ & $4.21 \%$ \\
\hline 5.48 & Yes & 0.36 & 0.06 & 0.150 & $3.14 \%[0.005]$ & $4.96 \%$ & $3.56 \%$ \\
\hline 7.02 & No & 0.36 & 0.06 & 0.001 & $4.58 \%[0.004]$ & $5.20 \%$ & $5.67 \%$ \\
\hline 7.02 & Yes & 0.36 & 0.06 & 0.150 & $4.81 \%[0.004]$ & $7.59 \%$ & $4.40 \%$ \\
\hline 8.66 & No & 0.36 & 0.06 & 0.001 & $4.70 \%[0.004]$ & $3.27 \%$ & $4.08 \%$ \\
\hline 8.66 & Yes & 0.36 & 0.06 & 0.150 & $4.85 \%[0.004]$ & $2.30 \%$ & $5.74 \%$ \\
\hline
\end{tabular}

$\bar{H}$ : incident wave height; $h$ : depth at wavemaker; $f_{\text {veg }}$ : calibrated friction coefficient of vegetated condition; $R M S$ : root mean square of difference between experimental and numerical $H_{s}$

Table 2: Application of Equation 6 and Equation 8 to field scale

\begin{tabular}{ccccccccc}
\hline $\boldsymbol{S}(\mathbf{m})$ & $\boldsymbol{h}_{\boldsymbol{c}}(\mathbf{m})$ & $\boldsymbol{H}_{\boldsymbol{o}}(\mathbf{m})$ & $\frac{\boldsymbol{S}^{\mathbf{2}}}{\boldsymbol{h}_{\boldsymbol{c}} \sqrt{\boldsymbol{H}_{o} \boldsymbol{h}_{\boldsymbol{c}}}}$ & $\frac{\boldsymbol{f}_{\boldsymbol{v e g}}}{\boldsymbol{f}_{\boldsymbol{c}}} \frac{\boldsymbol{H}_{\boldsymbol{o}}}{\boldsymbol{S}}$ & $\frac{\boldsymbol{U}_{\boldsymbol{c}}}{\boldsymbol{c}_{\boldsymbol{o}}}$ & $\frac{\boldsymbol{C}^{\mathbf{0 . 5}}}{\boldsymbol{h}_{\boldsymbol{c}}}$ & $\boldsymbol{U}_{\boldsymbol{c}}(\mathbf{m} / \mathbf{s})$ & $\boldsymbol{C}_{\left(\boldsymbol{m}^{2}\right)}$ \\
\hline 45 & 1 & 1.2 & 1848.6 & 0.267 & -0.054 & 11.673 & -0.431 & 136.3 \\
45 & 2 & 1.6 & 566.6 & 0.356 & -0.088 & 11.371 & -0.705 & 517.2 \\
45 & 3 & 2.2 & 262.7 & 0.489 & -0.110 & 11.046 & -0.884 & 1098.2 \\
40 & 2 & 1.6 & 447.2 & 0.400 & -0.095 & 11.250 & -0.760 & 506.3 \\
50 & 3 & 2.2 & 698.8 & 0.320 & -0.082 & 11.481 & -0.657 & 527.2 \\
\hline
\end{tabular}

$H_{o}$ : offshore wave height; $h_{c}$ : depth in the channels within wetlands. 
Figure 1

(a)
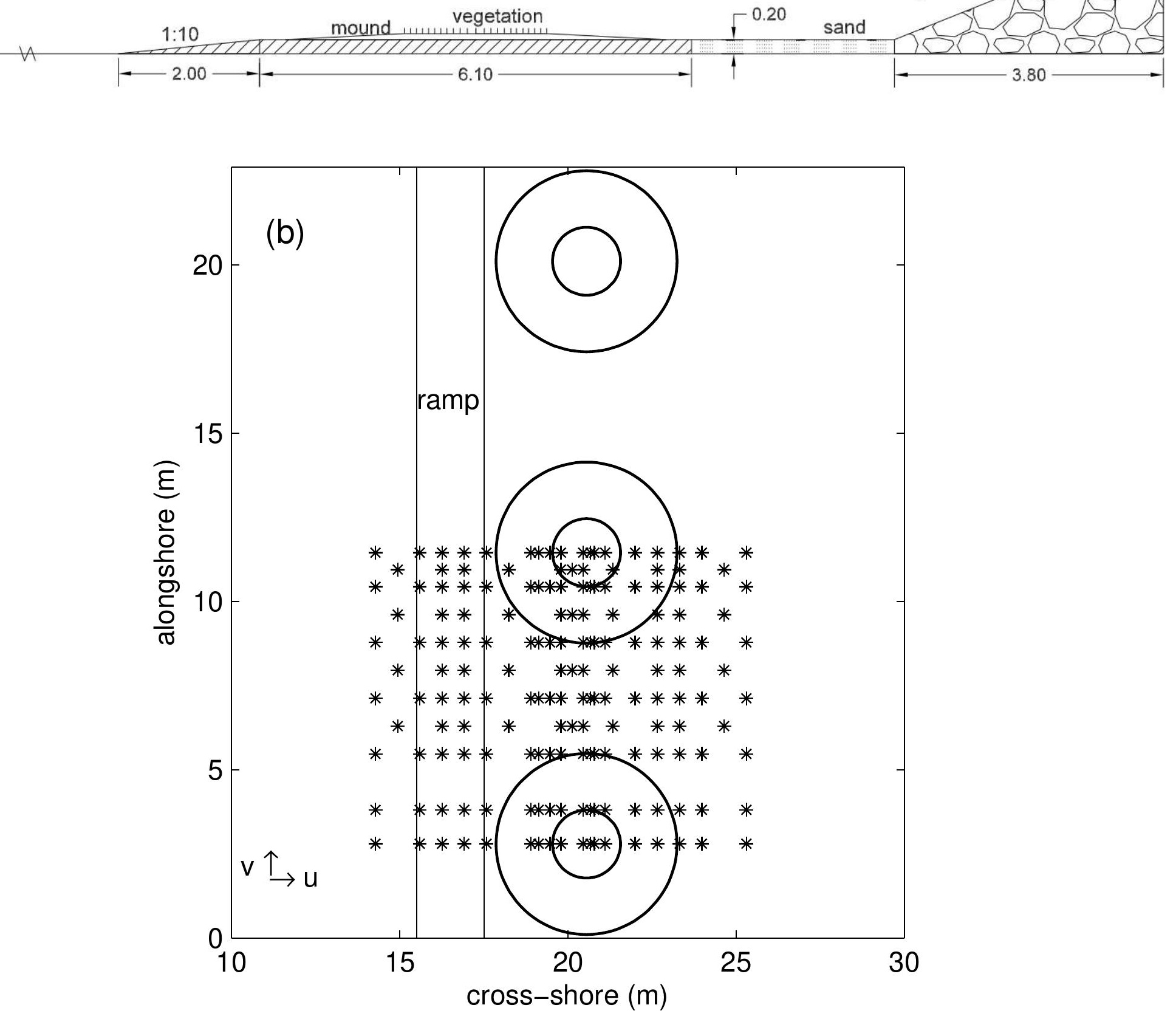

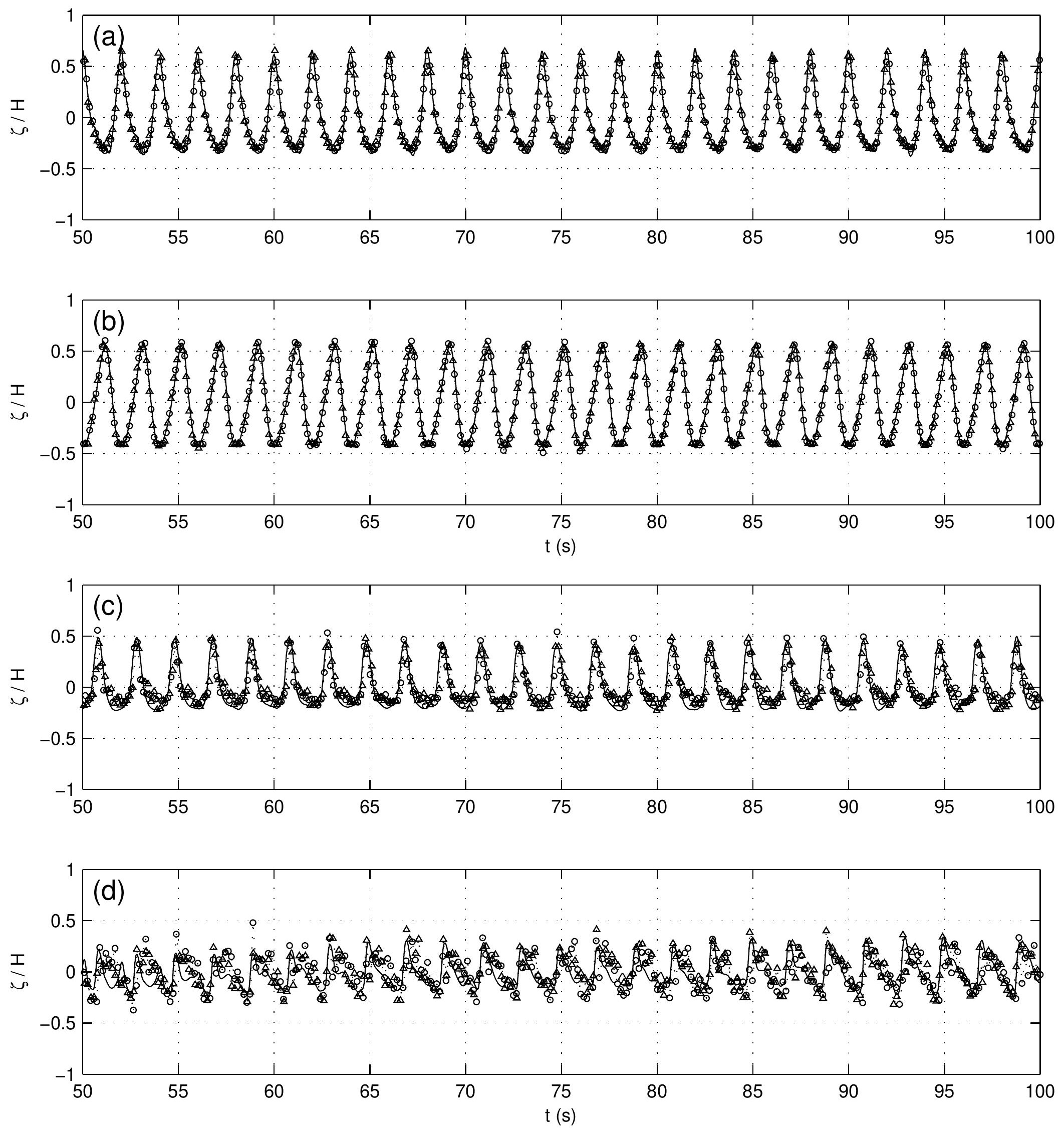

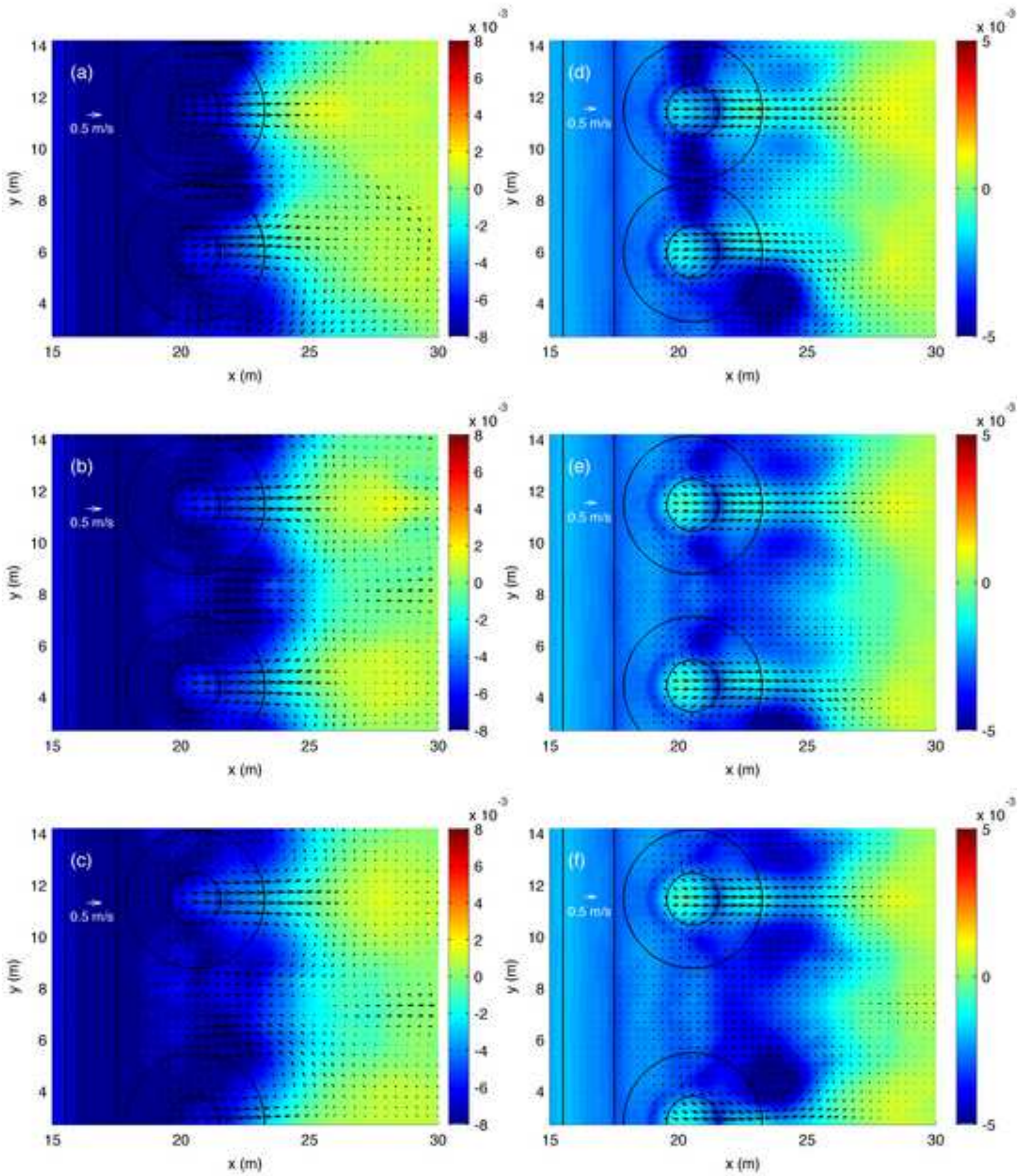


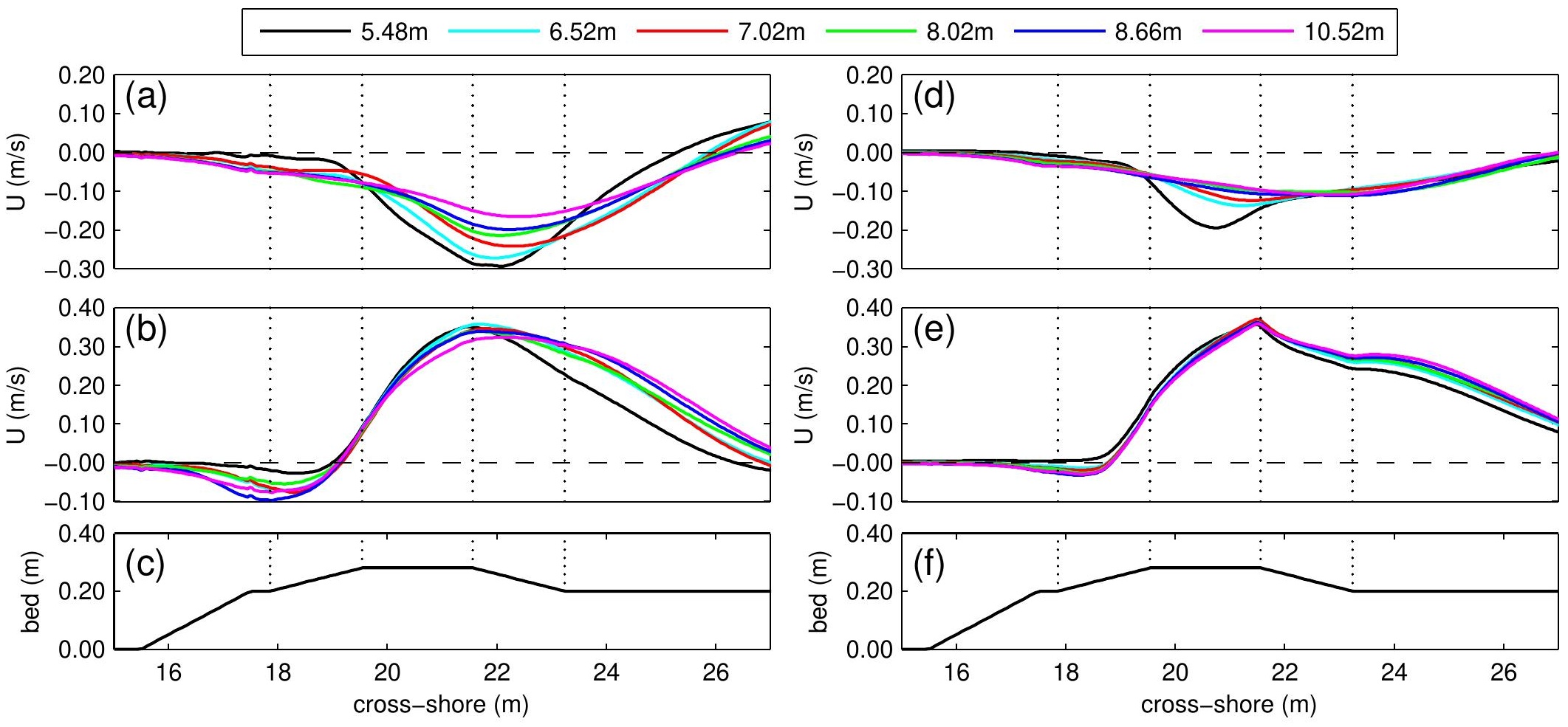




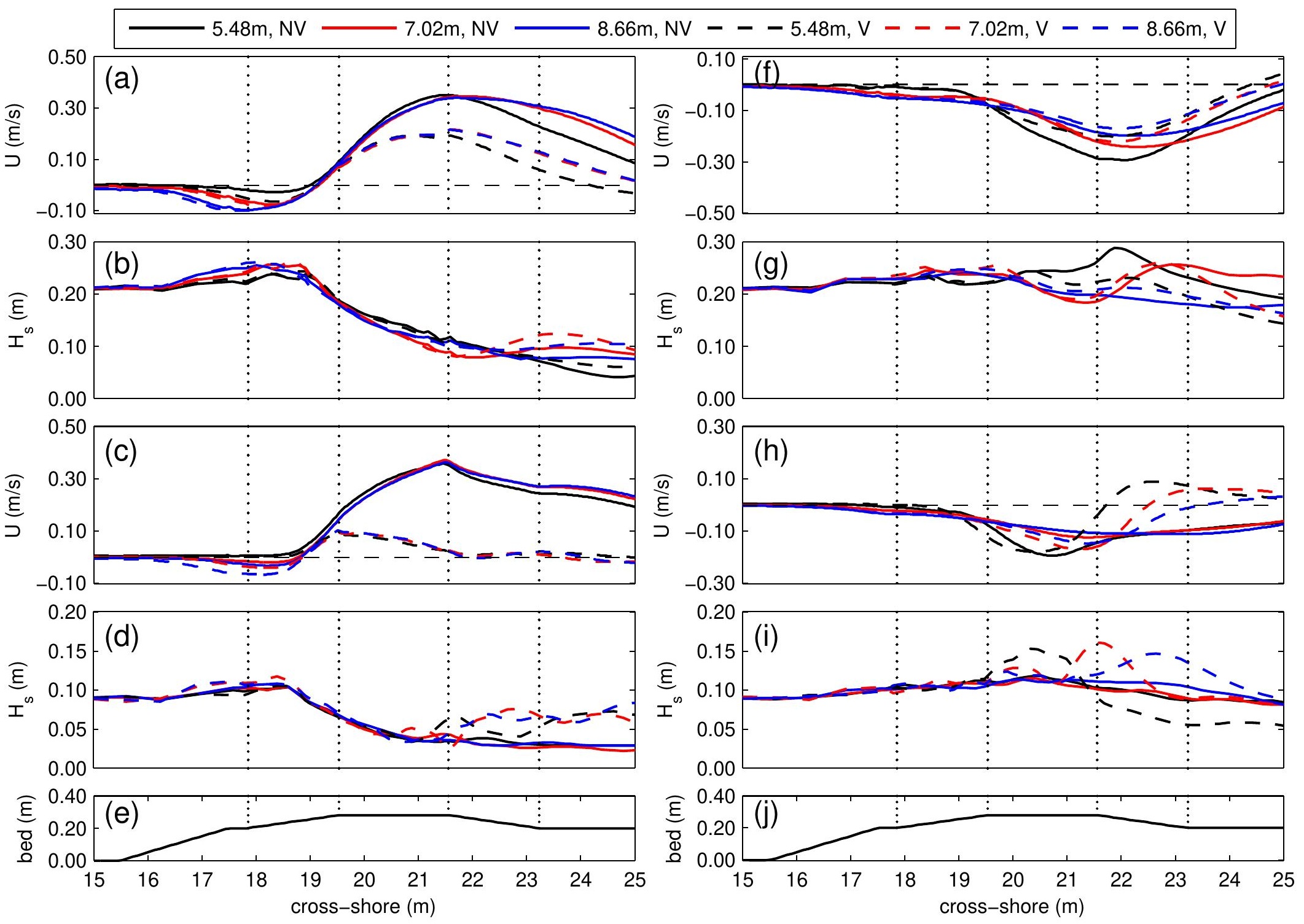




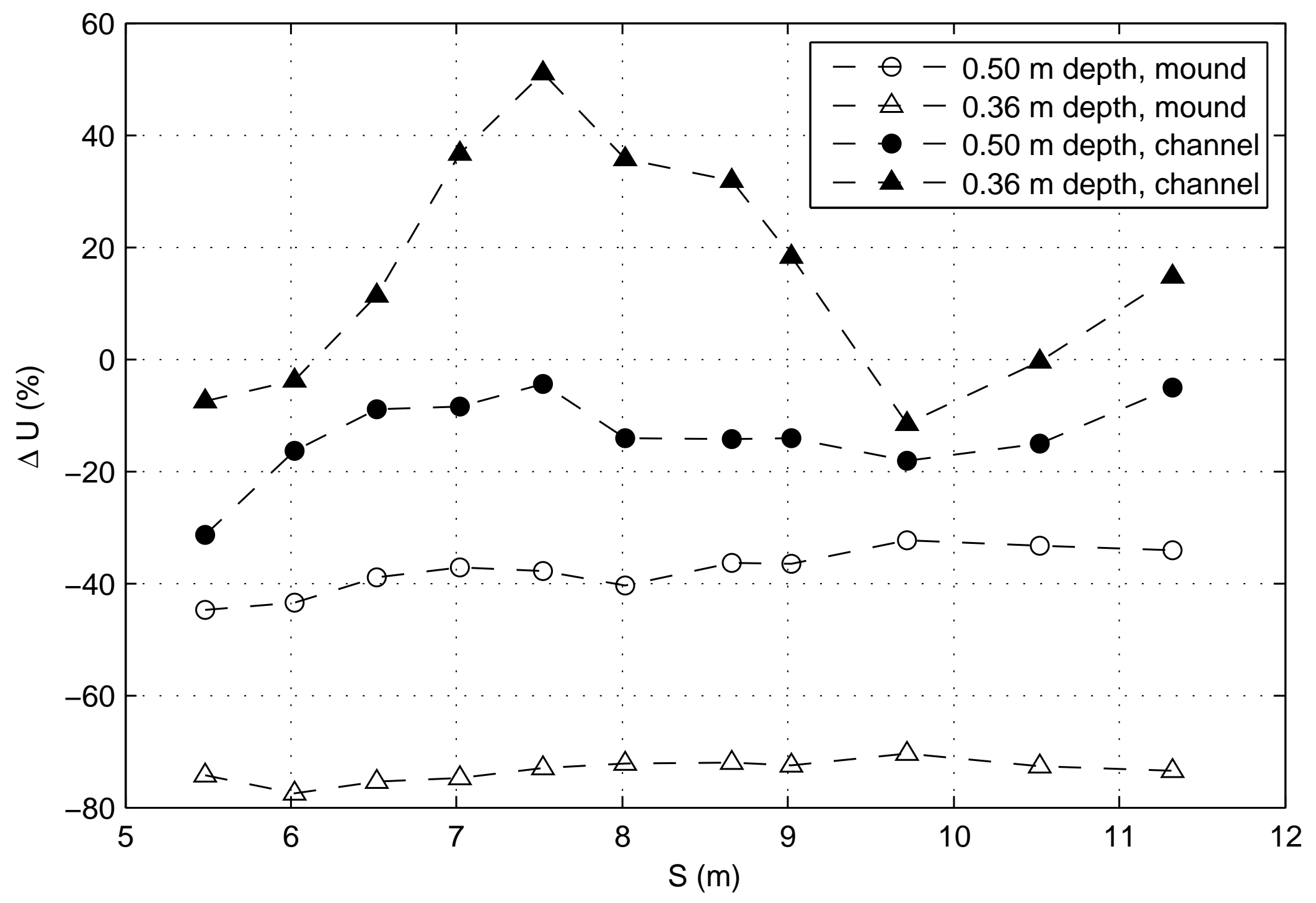



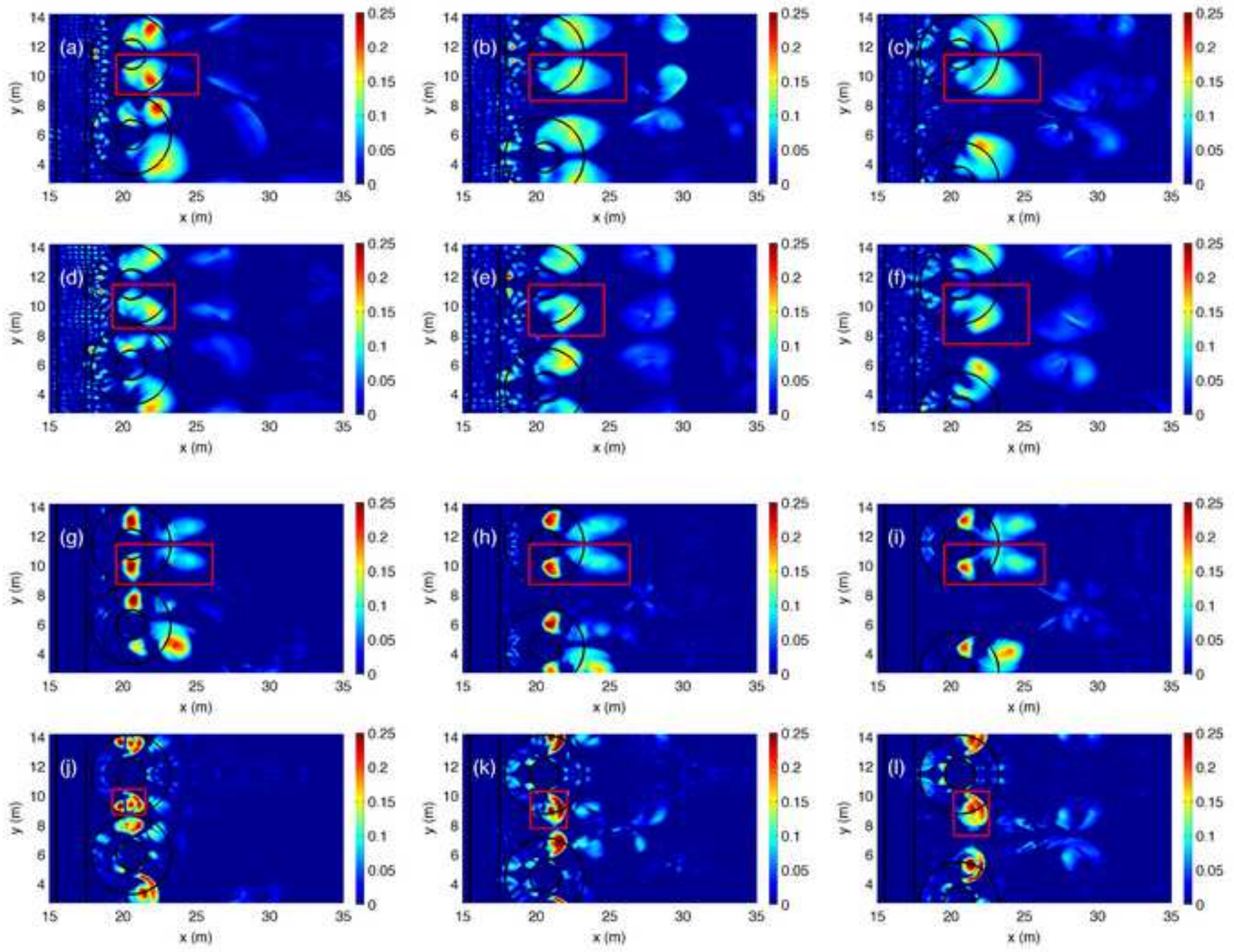


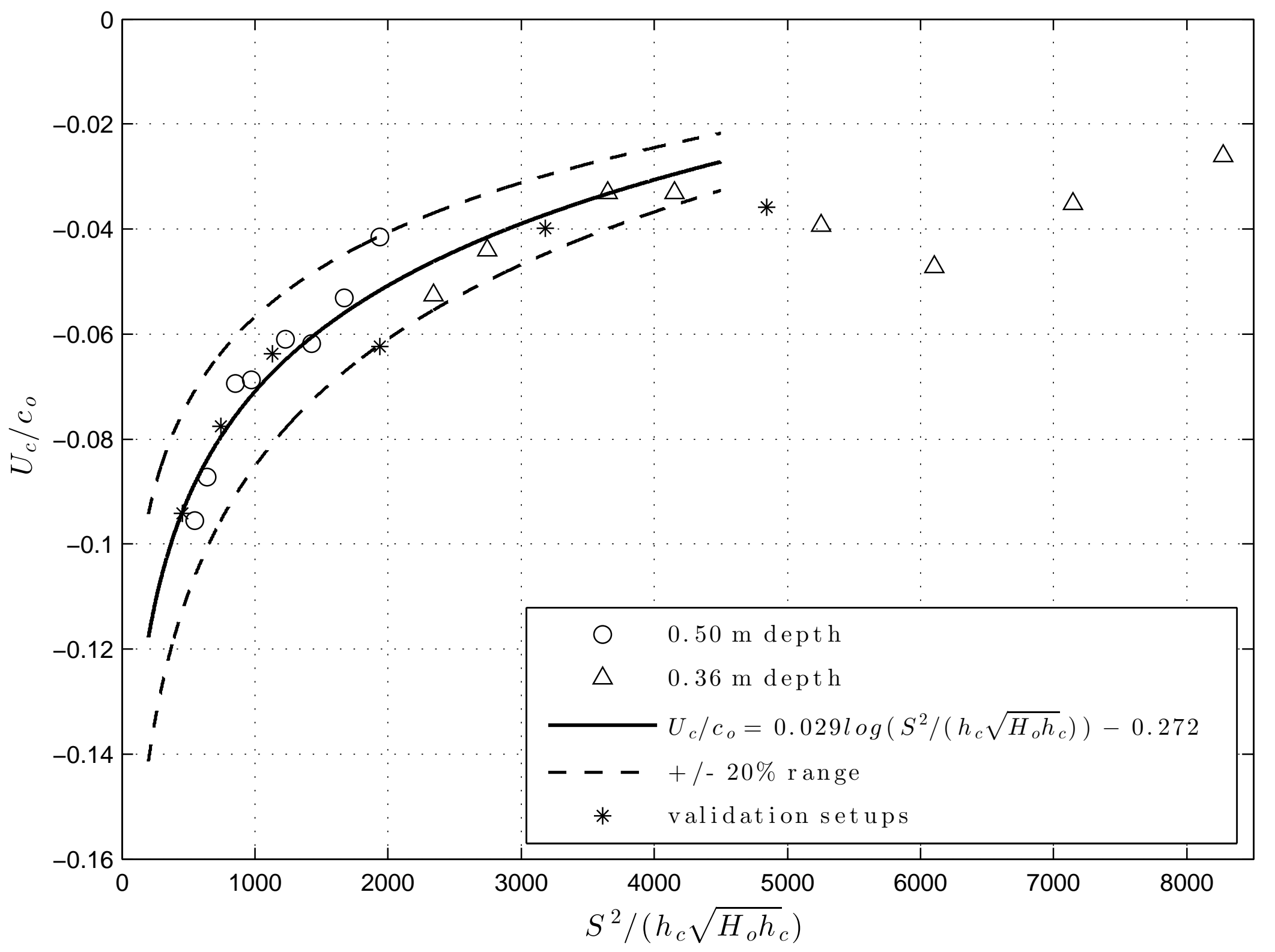




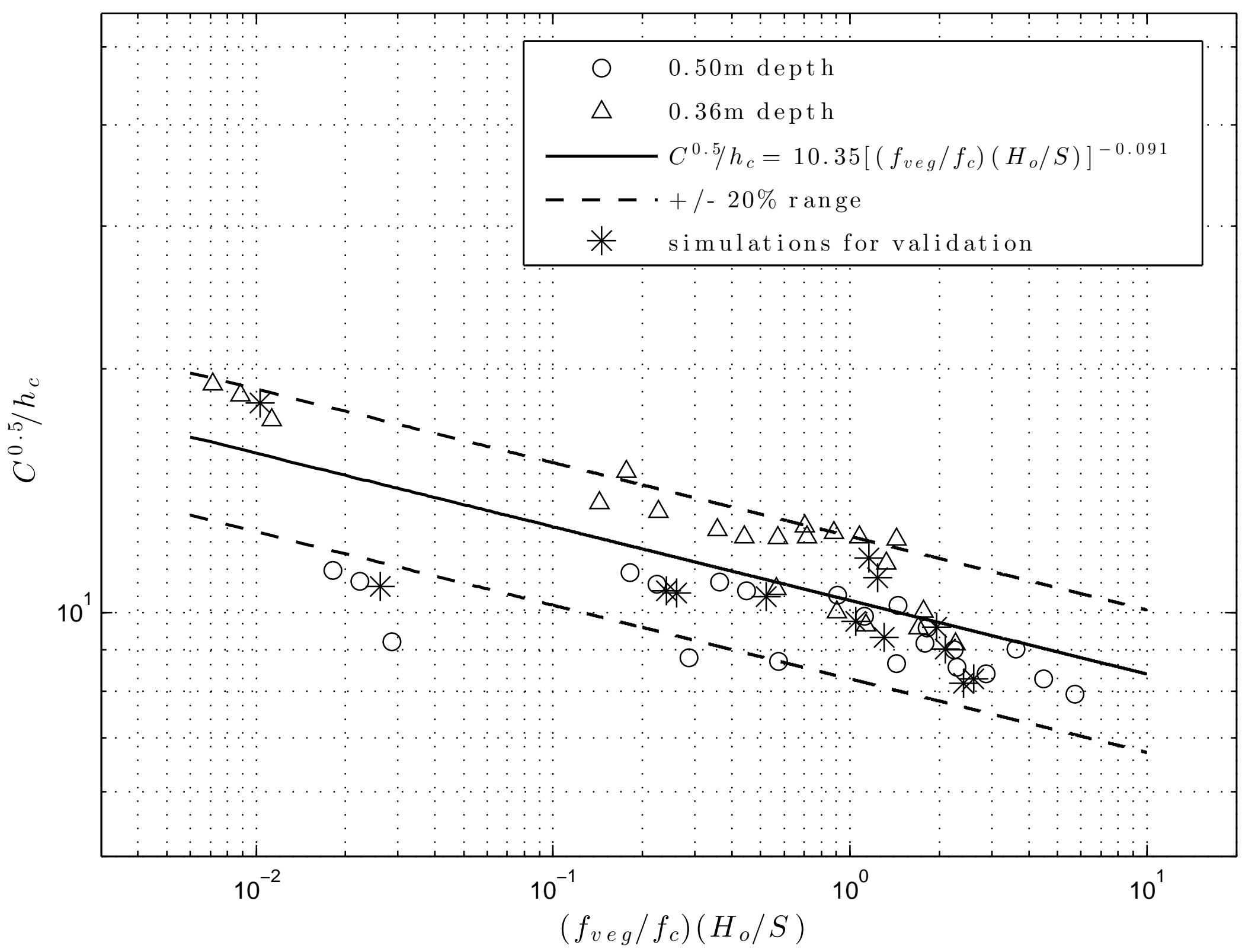

